GRASAS Y ACEITES 72 (4)

October-December 2021, e439

ISSN-L: 0017-3495

https://doi.org/10.3989/gya.0885201

\title{
Comparative study of the physicochemical properties of a vegan dressing-type mayonnaise and traditional commercial mayonnaise
}

\author{
$\oplus$ D.A. Cerro ${ }^{\mathrm{a}}, \oplus$ A.P. Maldonado ${ }^{\mathrm{a}}$ and $\odot$ S.B Matiacevich ${ }^{\mathrm{a}, 凶}$ \\ ${ }^{a}$ Food Science and Technology Department, Faculty of Technology, Universidad de Santiago de Chile, Obispo Umaña 050; 9170201, \\ Santiago. Chile. \\ ${ }^{\otimes}$ Corresponding author: silvia.matiacevich@usach.cl
}

Submitted: 01 August 2020; Accepted: 10 December 2020; Published online: 12 January 2022

SUMMARY: The food industry has developed a vegan dressing-type mayonnaise due to new consumer demands. The aim of this study was to compare three commercial mayonnaise types with a vegan dressing, measuring their physicochemical properties. Four dressing samples were analyzed: vegan, homemade recipe, creamy, and light. The following properties were measured: water activity, color, droplet size, rheological properties, structural analysis, and oxidative stability. A high color difference was observed between vegan and the other samples due to the presence of chickpea protein. The size and distribution of droplets of the vegan sample were greater than the others. The rheological properties indicated that all samples are non-Newtonian pseudoplastic fluids. The FT-IR results indicated that the highest peak for vegan corresponded to its content in mono-unsaturated fat. Therefore, it showed the lowest oxidative stability. In conclusion, the mayonaise formulations were affected by physicochemical properties such as the content and composition of the oil, thickener and protein contents, along with processing technology.

KEYWORDS: Emulsion; Mayonnaise; Physicochemical properties; Vegan

RESUMEN: Estudio comparativo de las propiedades fisicoquímicas entre una salsa vegana tipo mayonesa con respecto a las mayonesas comerciales tradicionales. La industria alimentaria ha desarrollado salsas tipo mayonesa veganas debido a los nuevos requerimientos de los consumidores. El objetivo de este trabajo fue comparar tres tipos de mayonesas comerciales (receta casera, cremosa y ligera) con una salsa vegana tipo también comercial, midiendo sus propiedades fisicoquímicas. Se midió actividad de agua, color, tamaño de gota, propiedades reológicas, análisis estructural y estabilidad oxidativa. Una gran diferencia de color fue observada entre la muestra vegana en comparación con las otras muestras debido a la presencia de proteínas de garbanzo. El tamaño y distribución de gotas y la estabilidad oxidativa de esta salsa fueron mayores en comparación con las otras muestras. Las propiedades reológicas indicaron que todas las muestras son fluidos pseudoplásticos no newtonianos. Los resultados de FT-IR indicaron que el pico más alto de la salsa vegana corresponde a grasas monoinsaturadas por esto mostró la menor estabilidad oxidativa. En conclusión, la formulación de cada tipo de salsa afectó sus propiedades fisicoquímicas.

PALABRAS CLAVE: Emulsión; Mayonesa; Propiedades físico químicas; Vegano

Citation/Cómo citar este artículo: Cerro DA, Maldonado AP, Matiacevich SB. 2021. Comparative study of the physicochemical properties of a vegan dressing type mayonnaise and traditional commercial mayonnaise. Grasas Aceites 72 (4), e439. https://doi.org/10.3989/ gya.0885201

Copyright: (C2021 CSIC. This is an open-access article distributed under the terms of the Creative Commons Attribution 4.0 International (CC BY 4.0) License. 


\section{INTRODUCTION}

An emulsion is a thermodynamically unstable dispersion of two immiscible liquids, usually apolar and polar, which forms small droplets ( 0.1 to 100 microns); one is called the dispersed or internal phase and the other, continuous or external phase (Muñoz et al., 2007). Emulsions are classified according to their composition as simple emulsions such as oil-in-water $(\mathrm{O} / \mathrm{W})$, water-in-oil ( $\mathrm{W} / \mathrm{O})$, or multiple emulsions such as water-in-oil-in-water emulsions $(\mathrm{W} / \mathrm{O} / \mathrm{W}$ ) and oil-in-water-in-oil (O / W / O) (Noon et al., 2020).

Mayonnaise is a type of oil-in-water $(\mathrm{O} / \mathrm{W})$ emulsion. It is defined as a condiment in the form of a dressing obtained by emulsifying edible vegetable oil(s) in an aqueous phase consisting of vinegar, and the addition of egg yolk produces the oil-in-water emulsion; besides, salt and seasonings can be added (Codex-Stan, 1989). Traditional mayonnaise contains $70-80 \mathrm{~g} / 100 \mathrm{~g}$ of fat and is one of the most commonly consumed dressing worldwide (Chang et al., 2017). Its structure, creaminess, appearance, and rheological behavior are of great importance for sensory properties and perceived texture, as well as for physical stability, parameters that represent critical factors in determining consumer choice and satisfaction (Di Mattia et al., 2015).

Nowadays, food preferences have been changing, either by controlling and avoiding degenerative diseases associated with food or having healthier and even environmentally-friendly lifestyles (Park et al., 2020). In this sense, the consumption of low-fat foods has become a trend, mostly to avoid the development of cardiovascular diseases, obesity, and cancer (Jiménez-Colmenero et al., 2013). However, oil is an essential component in the elaboration of mayonnaise, and it plays an important role in its physicochemical and sensory characteristics (Zia-ud-Din et al., 2017). That is why the food industry has developed new formulations using additives which allow it to maintain the characteris- tics of a traditional mayonnaise but with a low oil content (Depree and Savage, 2001; Shen et al., 2011). Within traditional mayonnaise, there is also a difference in the type of oil used, the most common being soybean, sunflower, corn and rapeseed oils (Di Mattia et al., 2015).

On the other hand, recent consumer-conscious demands for healthy foods have increased. Moreover, vegan customers cannot eat egg-based foods. These new dietary trends impact mayonnaise formulations (Ali and EL Said, 2020). So it is possible to find mayonnaise on the market which is free of animal components, known as vegan mayonnaise or also called vegan dressings (Cornelia et al., 2015). Although this type of dressing is called vegan mayonnaise, international regulations do not define it since the term mayonnaise corresponds to the definition described above. For the formulation of vegan dressing, the use of eggs is replaced by legumes such as beans, soybeans, chickpea, white lupine, wheat protein, and a germ protein isolate (Ali and EL Said, 2020).

Mirzanajafi-Zanjani et al. (2019) reported that each dressing component formulation has a specific role, where increasing or decreasing each particle size could influence the mayonnaise's consistency, stability, and the sensory properties of the product's antioxidant stability. Raikos et al. (2020) studied a commercially canned chickpea aquafaba as an egg substitute for the development of vegan mayonnaise, showing that the phenolic compounds and saponins of aquafaba have antioxidant potential and rheological properties such as foaming, emulsifying and gelling properties. It demonstrated that changes in formulations influence the physicochemical parameters of mayonnaise type-dressing; however, parameters such as water activity, particle size, color, and lipid oxidation were not determined.

Therefore, the aim of this study was to compare three types of commercial mayonnaise of different formulations (high in fat, traditional homemade recipe, and light) with

TABLE 1. Nutritional information of different samples.

\begin{tabular}{lcccc}
\hline Nutritional Fact & VEG & HOM & CRE & LIG \\
\hline Energy (kcal) & 615.0 & 392.0 & 706.0 & 140.0 \\
Proteins (g) & 0.9 & 0.7 & 0.6 & 0.5 \\
Total fat (g) & 63.8 & 40.5 & 76.0 & 11.2 \\
Saturated fat (g) & 3.7 & 4.8 & 12.0 & 1.4 \\
Monounsaturated fat (g) & 41.4 & 13.6 & 17.0 & 3.8 \\
Polyunsaturated fat (g) & 18.7 & 2.9 & 43.0 & 5.9 \\
Trans fatty acids (g) & 0.0 & 0.4 & 0.9 & 0.1 \\
Cholesterol (mg) & 0.0 & 21.0 & 26.0 & 15.6 \\
Carbohydrates (g) & 9.3 & 6.3 & 2.0 & 9.5 \\
Total sugars (g) & 1.0 & 3.5 & 2.0 & 4.5 \\
Sodium (mg) & 245.0 & 635.0 & 549.0 & 747.0 \\
Dietary fiber (g) & 0.0 & 0.0 & 0.0 & 0.0 \\
\hline
\end{tabular}

VEG: vegan dressing-type mayonnaise; HOM: homemade recipe mayonnaise; CRE: creamy mayonnaise; LIG: light mayonnaise 
TABLE 2. Ingredient lists of different samples.

\begin{tabular}{llll}
\hline \multicolumn{1}{c}{ VEG } & \multicolumn{1}{c}{ HOM } & \multicolumn{1}{c}{ CRE } & \multicolumn{1}{c}{ LIG } \\
\hline Canola oil & Water & Soy oil & Water \\
Water & Marigold and soy oils & Water & Marigold and soy oils \\
Chickpea & Pasteurized liquid whole egg & Pasteurized egg & Modified corn starch \\
Mustard seeds & Modified corn starch & Vinegar & Sugar \\
Grape vinegar & Sugar & Less than 2\% sugar & Pasteurized whole egg \\
Lemon juice & Alcohol vinegar & Salt & Alcohol vinegar \\
Salt & Salt & Pasteurized egg yolk & Salt \\
Brown sugar & Potassium chloride & Natural flavoring & Potassium chloride \\
White pepper & Sorbic acid & Lemon juice concentrate & Xanthan Gum \\
Dehydrated garlic & Xanthan Gum & Dehydrated garlic and onion & Sorbic and phosphoric acid \\
Peppers & Phosphoric acid & Peppers & Lemon juice concentrat \\
EDTA & Natural flavoring & EDTA & Antioxidants (BHA, propyl gallate, citric acid) \\
& EDTA & Calcium disodium & EDTA \\
& & & Natural identical smell \\
& & Beta carotene (synthetic) \\
\hline
\end{tabular}

VEG: vegan dressing-type mayonnaise; HOM: homemade recipe mayonnaise; CRE: creamy mayonnaise; LIG: light mayonnaise

a commercial vegan dressing-type mayonnaise, through its physical-chemical properties to determine the differences among the different types of dressings.

\section{MATERIALS AND METHODS}

\subsection{Materials}

The different samples were purchased from a local supermarket (Tottus), located in Santiago, Chile. The dressings were as follows: VEG (Notmayo, vegan dressing-type mayonnaise) as a control, HOM (Hellmans, traditional homemade recipe mayonnaise), CRE (Kraft, high-fat-mayonnaise), and LIG (JB, light-mayonnaise). Table 1 and Table 2 show the nutritional information and ingredient list for each of them, reported in labeled brands.

\subsection{Methods}

Physical properties such as water activity, average droplet size, rheological properties, and color measurement were measured along with the chemical properties FT-IR infrared spectroscopy and oxidative stability.

\subsubsection{Water activity (aw)}

The water activity meter (AquaLab Pre-water Activity Meter, United States) was used. The samples at $25 \pm 0.2$ ${ }^{\circ} \mathrm{C}$ were deposited to cover the entire plastic vessel.

\subsubsection{Droplet size and distribution}

$30 \mathrm{~mL}$ of sample were placed on a slide and viewed under a binocular vertical light microscope (Zeiss, Primo Star, England) using a $100 \mathrm{x}$ magnification at room temperature.
The images were captured with a remotely directed digital camera (Canon EOS Rebel T3, Canon Inc., Tokyo, Japan). The droplet size was determined from the images using the calibrated Motic Images Plus 2.0 software (Causeway Bay, Hong Kong). Drop size values were reported using the Sauter diameter $(\mathrm{d} 32)$ of at least 200 drops counted from 3 to 8 photos as required for each sample in triplicate $(n=600)$ (Alarcón-Moyano et al., 2017):

$$
d_{32}=\frac{\sum_{i=0}^{n} d_{i} n_{i}^{3}}{\sum_{i=0}^{n} d_{i} n_{i}^{2}}
$$

Where $\sum_{i=0}^{n} d_{i} n_{i}^{3}$ is the sum of the $\mathrm{d} 32$ corresponding to the drop volume. $\sum_{i=0}^{n} d_{i} n_{i}^{2}$ is the sum of the $\mathrm{d} 32$ corresponding to the droplet area.

\subsubsection{Color measurement}

The images of samples were captured on a black background through a calibrated computer vision system (LabVisionQ, Chile), according to the method described by Matiacevich et al. (2015). All images were acquired under the same conditions, with a remote camera controlled by the EOS Utility software (Canon Inc., Japan). They were analyzed using Adobe Photoshop v7.0 software to obtain RGB space parameters, converted to CIE L* $a^{*} b^{*}$ standard color space. The $\mathrm{L}^{*}, \mathrm{a}^{*}$, and $\mathrm{b}^{*}$ parameters represent lightness, the red-green axis, and the blue-yellow axis, respectively. The color difference index $(\Delta \mathrm{E} 00)$ was calculated using the CIEDE2000 equation. The perception of the color difference perceived by the human eye was determined according to the perception table described by (Yang et al., 2012). The yellowness index is measured according to the ASTM E313-73 method of opaque materials close to white. 


\subsubsection{Fourier transform infrared spectroscopy}

Fourier transform infrared spectroscopy (FT-IR) analysis was performed to identify the functional groups of oil and water of the different samples. For the analysis, FT-IR equipment with the attenuated total reflection instrument (ATR) was used, consisting of a diamond with an incidence angle unit of $45^{\circ}$ (Perkin-Elmer, USA). Enough sample was deposited to cover the diamond. Twenty-four scanners were performed per sample, at a wavelength of 1500 to $1900 \mathrm{~cm}^{-1}$ and resolution of $4 \mathrm{~cm}^{-1}$.

\subsubsection{Rheological properties}

The rheological properties were determined on a rotational rheometer (Rheolab QC, Anton-Paar, Austria), using a suitable concentric cylinder measurement geometry (C27, Anton Paar) to measure this type of more viscous samples. The samples were stabilized for $10 \mathrm{~min}$ before starting the measurement to ensure that the molecular structure returned to its initial state caused by placing the samples into the geometry. The temperature was controlled at $25{ }^{\circ} \mathrm{C}$, incorporating a temperature control device (C-PTD 180 / AIR / QC) with a Pt100 temperature sensor into the equipment. Two flow traps with up and down cycles corresponding to cut speeds in the range of 5 to $600 \mathrm{~s}^{-1}$ were obtained (Juszczak et al., 2003). The Herschel-Bulkley model described the curves obtained (Liu et al., 2007), whose adjustment and parameter determination was obtained by employing an iterative method with the Solver analysis tool of the Excel 2016 program.

\subsubsection{Oxidative stability RapidOxy ${ }^{\circledR}$ setup (pressurized headspace oxygen treatment method)}

The oxidative stability study was performed using a RapidOxy test device (RapidOxy, Anton Paar, Graz, Austria). It allowed the study of oxidative degradation reactions in a short period using a pressurized oxygen headspace over a solid sample in a closed oven set at a specific temperature. Experimentally, $5 \mathrm{~g}$ of sample were placed in a dish. The method parameters used were oxygen pressure of $700 \mathrm{kPa}$ at $120{ }^{\circ} \mathrm{C}$. The induction period (min) corresponds to the time required to cause the pressure to drop to $10 \%$.

\subsection{Statistical analysis}

All measurements were performed in triplicate. The results were reported using their average value and standard deviation of at least three measurements. The statistical analysis of these results was evaluated using the one-way ANOVA analysis of variance. For significant differences among samples, multiple comparisons were made using the Tukey test, with a significance level of
95\%, using the GraphPad Prism 5.01 software (GraphPad Prism Ink, USA).

\section{RESULTS AND DISCUSSION}

\subsection{Physical properties}

Water activity $(a w)$ is the water available for microbial development and/or development of biochemical reactions within a food. This property is related to how much food is perishable or not (Fenoglio et al., 2020). Regarding this property, Table 3 shows the results for the different samples, wherein in all cases, their values are high $(>0.9)$ due to the nature of the mayonnaise which corresponds to an oil emulsion with high water content. Where the CRE sample shows a slight significant $(\mathrm{p}<0.05)$ decrease in its water activity $(0.938 \pm 0.003)$, which may be because it is the sample with the highest fat content (Table 1). Besides, in the case of VEG, CAS, and LIG, the main ingredient is water ( $a w=0.973 \pm 0.003)$; while for CRE, it is oil, so decreasing the $a w$ value. This is corroborated in table 2, where the list of ingredients, which are in decreasing order of initial weight can be seen. The results obtained are comparable to the study carried out by Amin et al. (2014), where a low-fat mayonnaise was developed with different hydrocolloid gum types and levels. The results showed that water activity depended on oil concentration, where at $75 \%$ oil has a lower water activity $(0.89 \pm 0.01)$, while the sample with $45 \%$ oil increased its water activity $(0.94$ \pm 0.02 ). Considering that all samples showed high $a w$, it was necessary to add ingredients such as acetic acid, salt, and EDTA (Ethylenediaminetetraacetic acid) to control microbial and biochemical reaction developments. These contents can be observed in Table 2 .

Color is one of the most important properties which affects the appearance and acceptability of mayonnaise and the traditional mayonnaise recipe is characterized by a bright yellow appearance (Drozłowska et al., 2020). Table 4 shows the $L^{*} a^{*} b^{*}$ parameters, the color differences between traditional mayonnaise compared to VEG $(\Delta \mathrm{E}(00))$, and the yellowness index $(\mathrm{Y})$ of the different samples. For all samples, the color was significantly different $(\mathrm{p}<0.05)$ among samples. The highest $\mathrm{L}^{*}$ mean value corresponded to HOM, being the sample with the highest lightness, and VEG, the one with the least lightness. According to Mun et al. (2009), who mentions that the decrease in $\mathrm{L}^{*}$ parameter can be attributed to the presence of solid protein particles, the studied VEG sample showed the highest protein content (Table 1) and therefore, the lowest lightness (Table 4). At the same time, the lower L* parameter of the LIG sample is explained by the higher content of thickeners used in its formulation compared to the other samples (Amin et al., 2014). Low-fat mayonnaise obtained similar results to flaxseed meal extract (Drozłowska et al., 2020). The 
Comparative study of the physicochemical properties of a vegan dressing-type mayonnaise and traditional commercial mayonnaise 5

TABLE 3. Water activity, Droplet size, and oxidation induction time of different samples.

\begin{tabular}{lccc}
\hline \multicolumn{1}{c}{ Sample } & $\begin{array}{c}\text { Water activity } \\
(\boldsymbol{a} \boldsymbol{w}) \mathbf{n}=\mathbf{3}\end{array}$ & $\begin{array}{c}\text { Droplet size } \\
(\mathbf{u m}) \mathbf{n}=\mathbf{1 0 0}\end{array}$ & $\begin{array}{c}\text { Oxidation induction } \\
\text { time }(\mathbf{m i n}) \mathbf{n}=\mathbf{3}\end{array}$ \\
\hline VEG (control) & $0.974 \pm 0.004^{\mathrm{b}}$ & $27.3 \pm 3.7^{\mathrm{c}}$ & $183.8^{\mathrm{b}} \pm 1.5^{\mathrm{b}}$ \\
HOM & $0.973 \pm 0.003^{\mathrm{b}}$ & $15.7 \pm 3.2^{\mathrm{b}}$ & $201.3^{\mathrm{c}} \pm 4.1^{\mathrm{c}}$ \\
CRE & $0.938 \pm 0.004^{\mathrm{a}}$ & $13.8 \pm 2.1^{\mathrm{b}}$ & $144.0^{\mathrm{b}} \pm 2.7^{\mathrm{a}}$ \\
LIG & $0.976 \pm 0.003^{\mathrm{b}}$ & $8.4 \pm 1.7^{\mathrm{a}}$ & $215.6 \pm 7.3^{\mathrm{d}}$ \\
\hline
\end{tabular}

* Different letters above the columns indicate a significant difference $(\mathrm{p}<0.05)$ by Tukey test between the samples means $(\mathrm{n}=3$ or 100$)$. VEG: vegan dressing-type mayonnaise; HOM: homemade recipe mayonnaise; CRE: creamy mayonnaise; LIG: light mayonnaise

TABLE 4. Color parameters of different samples.

\begin{tabular}{lccccc}
\hline \multirow{2}{*}{ Sample } & \multicolumn{5}{c}{ Color Parameters } \\
\cline { 2 - 5 } & $\mathbf{L}^{*}$ & $\mathbf{a}^{*}$ & $\mathbf{b}^{*}$ & $\mathbf{Y}$ & $\Delta \mathbf{E}_{(00)}$ \\
\hline VEG (control) & $80.24 \pm 0.02^{\mathrm{a}}$ & $0.82 \pm 0.02^{\mathrm{a}}$ & $8.47 \pm 0.04^{\mathrm{a}}$ & $22.33 \pm 0.06^{\mathrm{a}}$ & - \\
HOM & $99.87 \pm 0.92^{\mathrm{d}}$ & $22.70 \pm 2.58^{\mathrm{d}}$ & $14.14 \pm 1.38^{\mathrm{b}}$ & $30.58 \pm 1.43^{\mathrm{b}}$ & $22.34 \pm 1.36$ \\
CRE & $98.19 \pm 0.24^{\mathrm{c}}$ & $8.51 \pm 0.18^{\mathrm{c}}$ & $17.17 \pm 0.59^{\mathrm{c}}$ & $27.31 \pm 0.70^{\mathrm{b}}$ & $14.73 \pm 0.24$ \\
LIG & $92.06 \pm 0.25^{\mathrm{b}}$ & $4.93 \pm 0.24^{\mathrm{b}}$ & $9.14 \pm 0.65^{\mathrm{a}}$ & $21.49 \pm 2.11^{\mathrm{a}}$ & $9.34 \pm 0.30$ \\
\hline
\end{tabular}

* Different letters above the columns indicate a significant difference $(\mathrm{p}<0.05)$ by Tukey test between the samples means $(\mathrm{n}=3)$. L: lightness, Y: yellowness index, $\Delta \mathrm{E}(00)$ : color difference index. VEG: vegan dressing-type mayonnaise; HOM: homemade recipe mayonnaise; CRE: creamy mayonnaise; LIG: light mayonnaise

$\mathrm{a}^{*}$ and $\mathrm{b}^{*}$ parameters indicate the tendency towards red or green and yellow or blue, respectively, if it is a positive or negative value. In all samples, $a^{*}$ and $b^{*}$ showed significant differences $(\mathrm{p}<0.05)$ among samples, where positive values were obtained for both parameters, so a tendency towards red and yellow, respectively. In the VEG sample, $b^{*}$ value and yellowness index $(\mathrm{Y})$ were lower than the other samples because the chickpea's protein content controls these color parameters. Similar results were reported by Raikos et al. (2020) for a vegan mayonnaise using canned chickpea aquafaba, where the sample that contained a greater quantity of aquafaba indicated a lower value of $b^{*}$ and therefore of Y. On the other hand, the HOM sample showed the highest a* value $=22.70 \pm 2.58$, but CRE samples showed the highest $b *$ value $=17.17 \pm 0.59$. Therefore, HOM and CRE samples showed the highest lightness and yellowness index (Table 4). These characteristics belong to a type of traditional homemade mayonnaise with high oil contents (Chang et al., 2017). The color difference $(\Delta \mathrm{E} 00)$ is also observed in Table 4, according to the perceived scale of the color difference among samples proposed by (Yang et al., 2012). A significant color difference in VEG (control) with other samples is between VEG and HOM with an $\triangle \mathrm{E} 00$ value of $22.34 \pm 1.36$, which can be due to the highest $\mathrm{Y}$ value in sample HOM $(31 \pm 1)$. In contrast, a lower value for $\Delta \mathrm{E} 00(9.34 \pm 0.30)$ was determined between VEG and LIG, although notable differences were observed. Finally, the color change and color perception of each formulation can be attributed to the presence of thickeners, fat, and protein contents.

The microstructure of mayonnaise was determined by different factors, including the type and concentration of emulsifiers used to form the emulsion, the viscosity of the aqueous phase, the oil content, and the droplet size (Laca et al., 2010). Droplet size is an important parameter to predict the physical stability of emulsions (Arancibia et al., 2017), with high stability in small droplet size and significant impact on the rheological properties of the final product (McClements, 2012). Table 3 shows the droplet size results, and Figure 1 presents the optical micrographs of the different samples, where significant differences $(\mathrm{p}<0.05)$ between samples were observed. For VEG, the largest droplet sizes were obtained with a homogenous monomodal droplet population of $27.3 \pm 3.7 \mu \mathrm{m}$. Between HOM and CRE the mean sizes were $15.7 \pm 3.2$ and $13.8 \pm 2.1 \mu \mathrm{m}$, respectively, with spherical shapes of the oil droplets and different populations; while the smallest size was for the LIG sample of $8.4 \pm 1.7 \mathrm{um}$. In the case of the LIG sample, the droplet size was similar to a study conducted by Drozłowska et al. (2020). for a light mayonnaise with substitution of oil for flaxseed protein $(5,10$, and $15 \%)$, where the droplet sizes of the analyzed samples were 9.4, 9.6 and $8.2 \mu \mathrm{m}$, respectively. Similar values were also reported by Worrasinchai et al. (2006) (1-9 $\mu \mathrm{m})$ and Laca et al. (2010) (3 to $12 \mu \mathrm{m})$. The smaller droplet size can be attributed to two factors, a low oil concentration and the presence of a thickener. In the LIG sample, the main ingredients were water, oil, and mod- 
ified corn starch (thickener). In the study by Drozłowska et al. (2020), it was shown that the droplet size decreased with decreasing oil concentration and when replacing this ingredient with thickeners (proteins or polysaccharides) because the thickeners seemed to affect the development of the system due to their high emulsifying potential. Therefore, the thickener granules kert the oil droplets separated and prevented coalescence (Di Mattia et al., 2015). The stabilization of the mayonnaise's oil-water interface was mainly due to microparticles formed from the phosphoprotein and fused low-density lipoprotein constituents of egg yolk (Drozłowska et al., 2020).

In addition, Cornelia et al. (2015) related the size of the drops in mayonnaise made with egg protein to larger sizes than for vegan dressing-type mayonnaise due to the structure of animal origin proteins; therefore, similar results were expected in this study. However, the unexpected behavior of the VEG sample (the largest droplet size) could be attributed to the technology (type and processing conditions) used for the preparation of this dressing. Drozłowska et al. (2020) pointed out that it must be taken into account that the size of the particles and the differences in the colloidal state

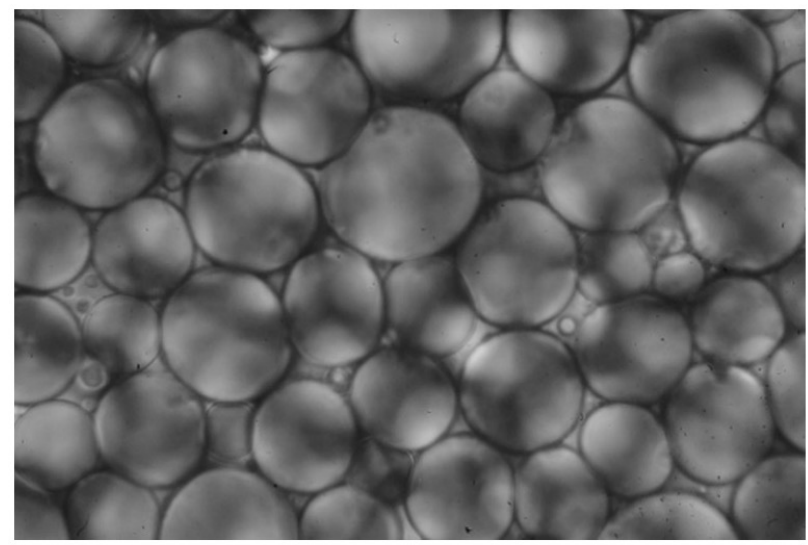

A: VEG

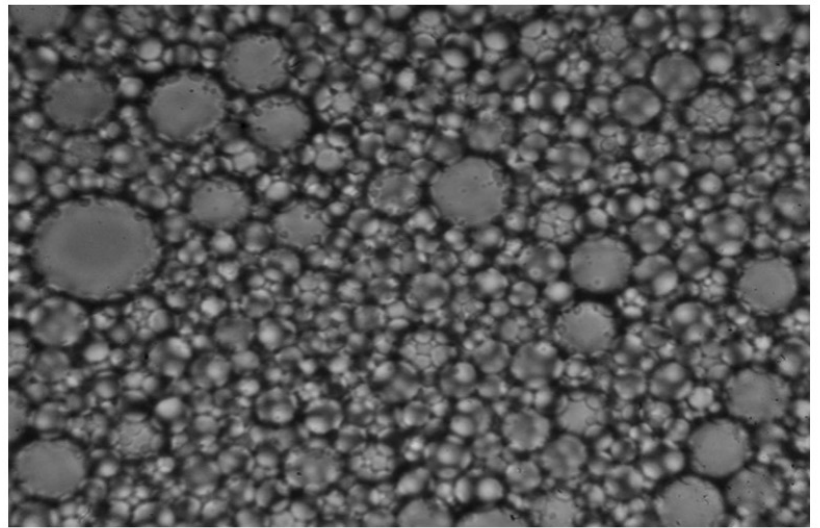

C: CRE can be attributed to the different ingredients and preparation processes that are used in the formulation of mayonnaise. Schultz et al. (2004) also indicated that the amount of energy required to produce such fine emulsions can generally only be achieved using high-pressure systems. Therefore, the droplet size parameter also depends on technological and process factors during manufacturing. For example, the homogenization technology used for the VEG emulsion might not be sufficient to decrease the droplet size in this mayonnaise. Therefore, greater physical instability, such as droplet agglomeration, is expected in this sample. However, regardless of the droplet size, the observed aggregation droplets (CRE $>$ VEG $>\mathrm{HOM}>\mathrm{LIG}$ ) (Figure 1) increased as the fat content increased $(76 \%>64 \%>41 \%>11 \%(\mathrm{w} / \mathrm{w})$, respectively) in the samples (Table 1).

\subsection{Rheological behavior}

Figure 2 shows the upward flow curves (upper curve) and downward flow curves (lower curve) of the different samples. The rheological parameters, such as yield stress, consistency index, flow behavior index, coefficient of determi-

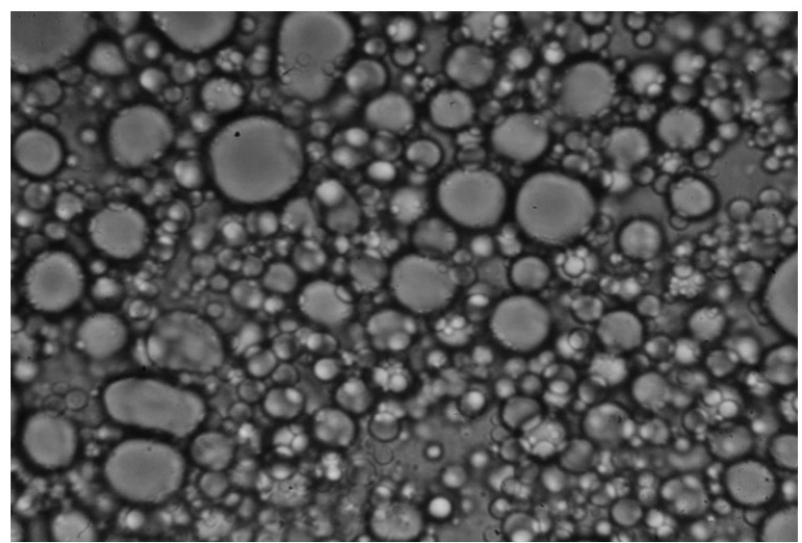

B: HOM

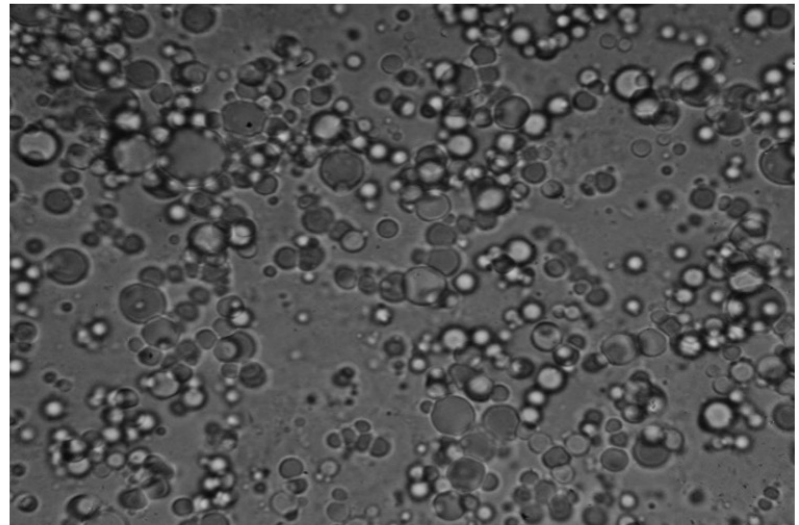

D: LIG

FiguRE 1. Optical micrographs for 100x magnification of different samples. A (VEG): vegan dressing-type mayonnaise, B (HOM): homemade recipe mayonnaise, $\mathrm{C}(\mathrm{CRE})$ : creamy mayonnaise, $\mathrm{D}$ (LIG): light mayonnaise 
TABLE 5. Rheological parameters of different samples

\begin{tabular}{lccccc}
\hline \multicolumn{1}{c}{ Sample } & $\begin{array}{c}\text { Yield Stress } \\
\boldsymbol{\sigma}_{\mathbf{o}} \mathbf{( P a )}\end{array}$ & $\begin{array}{c}\text { Consistency coefficient } \\
\mathbf{k}\left(\mathbf{P a} \cdot \mathbf{s}^{\mathbf{n}}\right)\end{array}$ & $\begin{array}{c}\text { Flow behaviour index } \\
\mathbf{n}(-)\end{array}$ & $\mathbf{R}^{2}$ & $\begin{array}{c}\text { Area of hysteresis } \\
\text { thixotropy loop }\left(\mathbf{P a ~ s} \cdot \mathbf{c m}^{3}\right)\end{array}$ \\
\hline VEG & $154.4 \pm 5.1^{\mathrm{c}}$ & $10.86 \pm 3.42^{\mathrm{c}}$ & $0.46 \pm 0.04^{\mathrm{a}}$ & 0.99965 & 105 \\
$\mathrm{HOM}$ & $143.9 \pm 0.7^{\mathrm{b}}$ & $1.73 \pm 0.04^{\mathrm{a}}$ & $0.70 \pm 0.01^{\mathrm{c}}$ & 0.99687 & 116 \\
CRE & $136.5 \pm 4.1^{\mathrm{b}}$ & $5.11 \pm 0.82^{\mathrm{b}}$ & $0.56 \pm 0.02^{\mathrm{b}}$ & 0.99892 & 110 \\
LIG & $85.5 \pm 1.1^{\mathrm{a}}$ & $14.72 \pm 0.78^{\mathrm{d}}$ & $0.44 \pm 0.01^{\mathrm{a}}$ & 0.99995 & 108 \\
\hline
\end{tabular}

* Different letters above the columns indicate a significant difference $(\mathrm{p}<0.05)$ by Tukey test between the samples means $(\mathrm{n}=3)$. $\mathrm{R}^{2}$ means a determination coefficient. VEG: vegan dressing-type mayonnaise; HOM: homemade recipe mayonnaise; CRE: creamy mayonnaise; LIG: light mayonnaise

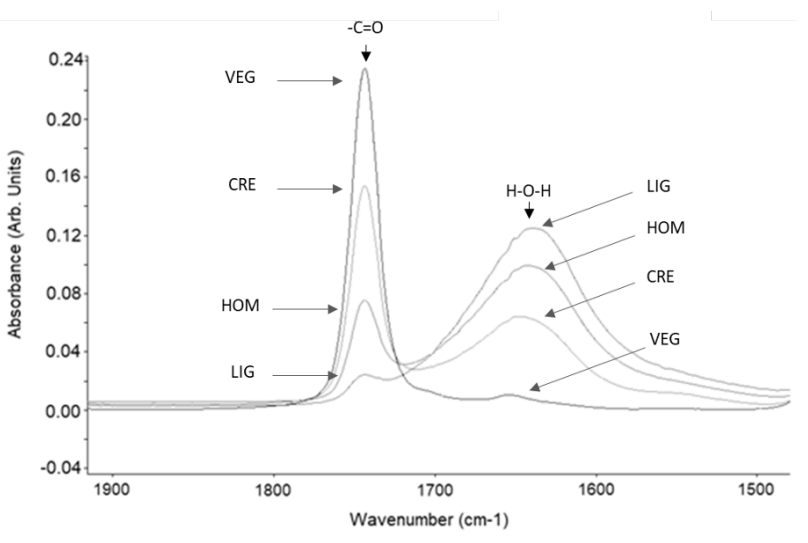

FIGURE 2. Fourier transform Infrared spectra of different samples. VEG: vegan dressing-type mayonnaise; HOM: homemade recipe mayonnaise; CRE: creamy mayonnaise; LIG: light mayonnaise

nation, and relative hysteresis area are detailed in Table 5. All the curves were fitted to the Herschel - Bulkley model and showed an excellent fit to the experimental data $\left(\mathrm{R}^{2}>0.995\right)$. Flow index values were lower than 1 , indicating that all the samples had a pseudoplastic flow behavior, typical of mayonnaise, which suggests that the samples were in semi-solid condition with breakable networks, which is in agreement with findings reported by (Liu et al., 2007; Li et al., 2014; Drozłowska et al., 2020). The pseudoplastic properties of mayonnaise may result from the flocculation and deflocculation of oil droplets, leading to the formation of two different size aggregates, which also affects the flow of mayonnaise (Sun et al., 2018). As the shear rate grows during the flow, the deflocculation phenomenon intensifies, thus decreasing the system's viscosity (Juszczak et al., 2003). Regarding the consistency coefficient, the highest value can be observed for the LIG sample. This behavior is explained by the presence of thickeners in its formulation, where the fat is replaced by a substitute based on carbohydrates such as modified corn starch (see Table 2). Hydrocolloid forms a gel-like structure, which traps oil droplets, slows down their movements, and increases viscosity, which is why this product can resemble the texture of traditional mayonnaise (Amin et al., 2014). This same phenomenon is related to the consistency index of the VEG sample corresponding to $10.86 \pm 3.42$, where this sample does not contain thickeners in its formulation (see table 2). However, this high consistency index is attributed to chickpea protein, a hydrocolloid that causes the same phenomenon as the thickeners.

The yield stress increased when the fat content increased (Peressini et al., 1998; Ma and Barbosa-Cánovas, 1995). In this study, LIG had less fat and a lower yield stress value $(85.5 \pm 1.1 \mathrm{~Pa})$. Ma and Barbosa-Canvas (1995) showed that yield stress for mayonnaise ranged from 23 to $235 \mathrm{~Pa}$, with similar data on yield stress ranging from this study (85.5154.4 Pa). The comparison between the ascending and descending flow curves determines the thixotropic hysteresis area of mayonnaise (Štern et al., 2001). Therefore, the viscosity changes were dependent on time, and related to the structural re-destruction degree of the product due to the shear (Primacella et al., 2019). The sample with the largest area was HOM (116). At the same time, VEG (105) had the smallest area, which may be advantageous in technological processes such as pumping, transport, or storage of the sample due to greater capacity to reconstruct damaged structure after removing shear forces. Studies indicated a relationship between fat content with a greater thixotropic area (Juszczak et al., 2003). However, this relationship was not found in this study because, in the formulation of the mayonnaises analyzed, the consistency was given mainly by the thickeners used to replace high-fat content. The stress threshold was associated with a three-dimensional network rupture of product structure. The obtained values were similar to the studies by Juszczak et al. (2003) for a Polish mayonnaise. The highest threshold stresses correspond to samples VEG 154.4 \pm 5.1, HOM 143.9 \pm 0.7 , and CRE $136.5 \pm 4.1$, and the lowest stress for LIG $85.5 \pm 1.1$, which is correlated with the lower fat content and smaller size of oil drops.

\subsection{Chemical properties}

The FT-IR spectra are presented in Figure 3. The characteristic peak of the H-O-H bands of the water at 1650 $\mathrm{cm}^{-1}$ is observed (Daoud et al., 2019), where it can be seen that in decreasing order, the peaks correspond to LIG > $\mathrm{HOM}>\mathrm{CRE}>\mathrm{VEG}$, which is related to the water content 


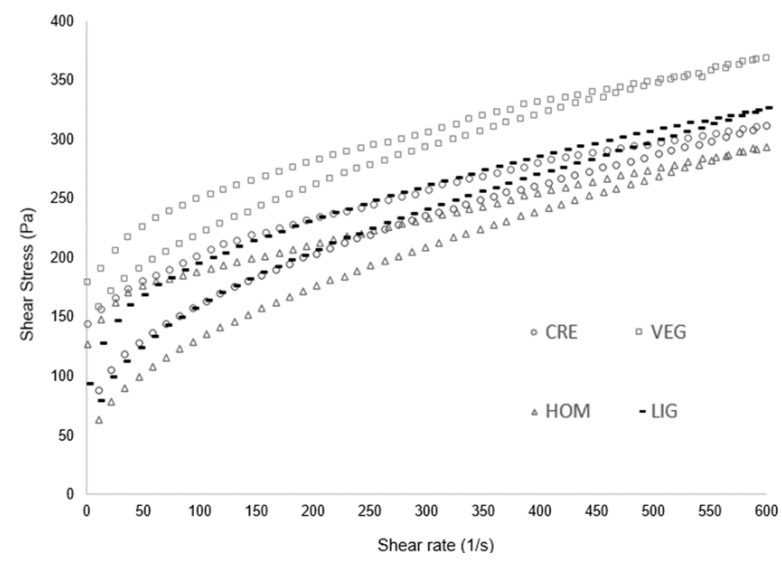

FIGURE 3. Flow curves of different samples. VEG: vegan dressing-type mayonnaise; HOM: homemade recipe mayonnaise; CRE: creamy mayonnaise; LIG: light mayonnaise

of the samples (Table 1). In contrast, CRE and VEG have water as the second-largest component and oil as the first, which is why it showed lower peak height.

The mono-unsaturated oil characteristic peaks of the bands $-\mathrm{C}=\mathrm{O}$ at $1750 \mathrm{~cm}^{-1}$ (Rohman et al., 2011), attributed to the triacylglycerides ester bonds, can be observed in figure 3. The decreasing peak area corresponds to VEG> CRE $>$ HOM $>$ LIG. This relationship was supported by the nutritional information (Table 1) of the different samples of monounsaturated fats, where they contain $41 \%>$ $17 \%>14 \%>4 \%(\mathrm{w} / \mathrm{w})$, respectively. Similar studies of quantitative analysis of fat and water content in mayonnaise using the FT-IR technique were performed by Chippie et al. (2002), and demonstrated a linear relationship between its composition and the height of the peaks.

Oxidative stability is the resistance of samples to be oxidized by the content of fats or other lipids when they come into contact with atmospheric oxygen (Miguel et al., 2019). Mayonnaise is a high-fat food $(70 \%-80 \%$ vegetable oil) and therefore is susceptible to oxidative deterioration through the auto-oxidation of the unsaturated and polyunsaturated fats in the oil, which depending on the extent, is likely to have a negative impact on flavor, aroma, color and nutritional value of food (Depree and Savage, 2001). Several strategies can be effective against the lipid oxidation of mayonnaise, such as the addition of antioxidants or the use of a lipid source that is naturally rich in compounds with potent antioxidant activity (Li et al., 2014; Di Mattia et al., 2015). Table 3 shows the results of the lipid oxidation induction time. These values may be influenced by the antioxidant content used in the different samples. Although all the samples contain EDTA as an antioxidant and preservative component, the labels do not specify the amount incorporated into them. However, it was possible to relate the results obtained with the content of polyunsaturated fats that are available to be oxidized due to instability and greater resonance of the double bonds exposed to oxygen (Roman et al., 2019). The LIG sample had the highest induction time of $216 \pm 7 \mathrm{~min}$ and the lowest content of these fats with only $6 \% \mathrm{w} / \mathrm{w}$, followed by HOM with a time of $201 \pm 4$ min with $22 \% \mathrm{w} / \mathrm{w}$. Similar results were found for the VEG sample with time and content of $184 \pm$ $2 \mathrm{~min}$ and $19 \% \mathrm{w} / \mathrm{w}$. Finally, CRE, with $144 \pm 3 \mathrm{~min}$ and the highest polyunsaturated fats content, with $43 \% \mathrm{w} / \mathrm{w}$. Therefore, as the increasing content of polyunsaturated fats in the samples, they will oxidize faster, one factor for this type of product's shelf-life.

\section{CONCLUSIONS}

A vegan dressing-type mayonnaise (VEG sample), free of animal origin components, showed differences in the physicochemical properties compared to traditional alternatives. It was attributed to its oil composition, the addition of thickeners and proteins, and process conditions. As expected, all the samples showed high water activity (aw $>0.9)$ and pseudoplastic flow behavior. The addition of vegetable proteins (chickpea) in VEG samples modified the color (being less light) and consistency parameter (increasing consistency index). Regarding the visual appearance, the VEG sample's color parameter presented the lowest $\mathrm{L}^{*}$ value, and a notable color difference was observed compared to the LIG and HOM samples. The HOM sample was precisely the yellowest and brightest sample. The largest droplet size was also observed for VEG samples, attributed to its higher oil content and emulsification technology. The high polyunsaturated fat contents led to the VEG and LIG samples showing lower oxidative stability with a shorter induction time. Thus, when a new formulation of vegan dressing-type mayonnaise is designed, it is useful to make the set of measurements described to obtain the same properties, mainly oxidative stability.

\section{REFERENCES}

Ali MR, EL Said RM. 2020. Assessment of the potential of Arabic gum as an antimicrobial and antioxidant agent in developing vegan "egg-free" mayonnaise. J. Food Saf. 40 (2), e12771. https:// doi.org/10.1111/jfs. 12771

Alarcón-Moyano JK, Bustos RO, Herrera M, Matiacevich SB. 2017. Alginate edible films containing microencapsulated lemongrass oil or citral: effect of encapsulating agent and storage time on physical and antimicrobial properties. $J$. Food Sci. Tech. 54 (9), 2878-2889. https://doi. org/10.1007/s13197-017-2726-1

Amin MHH, Elbeltagy AE, Mustafa M, Khalil AH. 2014. Development of low fat mayonnaise con- 
taining different types and levels of hydrocolloid gum. Journal of Agroalimentary Processes and Technologies 20 (1), 54-63.

Arancibia C, Riquelme N, Zúñiga R, Matiacevich S. 2017. Comparing the effectiveness of natural and synthetic emulsifiers on oxidative and physical stability of avocado oil-based nanoemulsions. Inn. Food Sc. Em. Tech. 44, 159-166. https://doi. org/10.1016/j.ifset.2017.06.009

Chang C, Li J, Li X, Wang C, Zhou B, Su Y,Yang Y. 2017. Effect of protein microparticle and pectin on properties of light mayonnaise. LWT-Food Sc. Tech. 82, 8-14. https://doi.org/10.1016/j.lwt.2017.04.013

Chippie AL, Jamieson PR, Golt CM, Hsu CH, Martin Lo Y. 2002. Quantitative analysis of fat and moisture in mayonnaise using the Fourier Transform Infrared spectrometer. Int. J. Food Prop. 5 (3), 655-665. https://doi.org/10.1081/JFP-120015499

Codex Alimentarius Commission. 1989. Codex standard for mayonnaise (Regional European Standard) CODEXSTAN 168-1989. Codex Coordinating Committee for Europe.

Cornelia M, Siratantri T, Prawita R. 2015. The utilization of extract Durian (Durio zibethinus L.) seed gum as an emulsifier in vegan mayonnaise. Procedia Food Sc. 3, 1-18. https://doi. org/10.1016/j.profoo.2015.01.001

Daoud S, Bou-Maroun E, Dujourdy L, Waschatko G, Billecke N, Cayot P. 2019. Fast and direct analysis of oxidation levels of oil-in-water emulsions using ATR-FTIR. Food Chem. 293, 307-314. https://doi.org/10.1016/j.foodchem.2019.05.005

Depree J, Savage G. 2001. Physical and flavour stability of mayonnaise. Trends Food Sc. Tech. 12 (5), 157-163. https://doi.org/10.1016/S09242244(01)00079-6

Di Mattia C, Balestra F, Sacchetti G, Neri L, Mastrocola D, Pittia P. 2015. Physical and structural properties of extra-virgin olive oil based mayonnaise. LWT-Food Sc. Tech. 62 (1), 764-770. https://doi.org/10.1016/j.lwt.2014.09.065

Drozłowska E, Łopusiewicz Ł, Mężyńska M, Bartkowiak A. 2020. The effect of native and denaturated flaxseed meal extract on physiochemical properties of low fat mayonnaises. J. Food Meas. Charact. 14 (2), 1135-1145. https://doi. org/10.1007/s11694-019-00363-6

Fenoglio D, Soto-Madrid D, Alarcón-Moyano JK, Ferrario M, Guerrero S, Matiacevich S. 2020.
Active food additive based on encapsulated yerba mate (Ilex paraguariensis) extract: effect of drying methods on the oxidative stability of a real food matrix (mayonnaise). J. Food Sc. Tech. 1-11. https://doi.org/10.1007/s13197-020-04669-y

Jiménez-Colmenero F, Cofrades S, Herrero AM, Solas MT, Ruiz-Capillas C. 2013. Konjac gel for use as a potential fat analog for healthier meat product development: Effect of chilled and frozen storage. Food Hydrocol. 30 (1), 351-357. https://doi.org/10.1016/j.foodhyd.2012.06.015

Juszczak L, Fortuna T, Kośla A. 2003. Sensory and rheological properties of Polish commercial mayonnaise. Food/Nahrung. 47 (4), 232-235. https:// doi.org/10.1002/food.200390054

Laca A, Sáenz MC, Paredes B, Díaz M. 2010. Rheological properties, stability and sensory evaluation of low-cholesterol mayonnaises prepared using egg yolk granules as emulsifying agent. J. Food Eng. 97 (2), 243-252. https://doi. org/10.1016/j.jfoodeng.2009.10.017

Li J, Wang Y, Jin W, Zhou B, Li B. 2014. Application of micronized konjac gel for fat analog in mayonnaise. Food Hydrocol. 35, 375-382. https://doi. org/10.1016/j.foodhyd.2013.06.010

Liu H, Xu XM, Guo SD. 2007. Rheological, texture, and sensory properties of low-fat mayonnaise with different fat mimetics. LWT-Food Sc. Tech. 40 (6), 946-954. https://doi.org/10.1016/j. lwt.2006.11.007

Ma L, Barbosa-Cánovas GV. 1995. Rheological characterization of mayonnaise. Part II: Flow and viscoelastic properties at different oil and xanthan gum concentrations. J. Food Eng. 25 (3), 409-425. https://doi.org/10.1016/02608774(94)00010-7

Matiacevich S, Acevedo N, López D. 2015. Characterization of edible active coating based on alginate-thyme oil-propionic acid for the preservation of fresh chicken breast fillets. J. Food Proc. Pres. 39 (6), 2792-2801. https://doi.org/10.1111/ jfpp. 12530

McClements DJ. 2012. Nanoemulsions versus microemulsions: terminology, differences, and similarities. Soft Matter 8 (6), 1719-1729. https://doi. org/10.1039/C2SM06903B

Miguel GA, Jacobsen C, Prieto C, Kempen PJ, Lagaron JM, Chronakis IS, García-Moreno P J. 2019. Oxidative stability and physical proper- 
ties of mayonnaise fortified with zein electrosprayed capsules loaded with fish oil. J. Food Eng. 263, 348-358. https://doi.org/10.1016/j. jfoodeng.2019.07.019

Mirzanajafi-Zanjani M, Yousefi M, Ehsani A. 2019. Challenges and approaches for production of a healthy and functional mayonnaise sauce. Food Sc. Nutr. 7 (8), 2471-2484. https://doi.org/10.1002/ fsn3.1132

Mun S, Kim YL, Kang CG, Park KH, Shim JY, Kim YR. 2009. Development of reduced-fat mayonnaise using $4 \alpha$ GTase-modified rice starch and xanthan gum. Int. J. Biol. Macromol. 44 (5), 400-407. https://doi.org/10.1016/j.ijbiomac.2009.02.008

Muñoz J, Alfaro M, Zapata I. 2007. Avances en la formulación de emulsiones. Grasas Aceites $\mathbf{5 8}$ (1), 64-73. https://doi:10.3989/gya.2007.v58.i1.10

Noon J, Mills TB, Norton IT. 2020. The use of natural antioxidants to combat lipid oxidation in $\mathrm{O} / \mathrm{W}$ emulsions. J. Food Eng. 281, 110006. https://doi. org/10.1016/j.jfoodeng.2020.110006

Park JJ, Olawuyi IF, Lee WY. 2020. Characteristics of low-fat mayonnaise using different modified arrowroot starches as fat replacers. Int. J. Biol. Macromol. 153, 215-223. https://doi. org/10.1016/j.ijbiomac.2020.02.331

Peressini D, Sensidoni A, De Cindio B. 1998. Rheological characterization of traditional and light mayonnaises. J. Food Eng. 35 (4), 409-417. https://doi.org/10.1016/S0260-8774(98)00032-6

Primacella M, Wang T, Acevedo NC. 2019. Characterization of mayonnaise properties prepared using frozen-thawed egg yolk treated with hydrolyzed egg yolk proteins as anti-gelator. Food Hydrocol. 96, 529-536. https://doi.org/10.1016/j. foodhyd.2019.06.008

Raikos V, Hayes H, Ni H. 2020. Aquafaba from commercially canned chickpeas as potential egg replacer for the development of vegan mayonnaise: recipe optimisation and storage stability. Int. J. Food Sc. Tech. 55 (5), 1935-1942. https:// doi.org/10.1111/ijfs. 14427
Rohman A, Che Man YB, Hashim P, Ismail A. 2011. FTIR spectroscopy combined with chemometrics for analysis of lard adulteration in some vegetable oils. Cyta-J. Food. 9 (2), 96-101. https://doi. org/10.1080/19476331003774639

Roman GC, Jackson RE, Gadhia R, Roman AN; Reis J. 2019. Mediterranean diet: The role of long-chain $\omega-3$ fatty acids in fish; polyphenols in fruits, vegetables, cereals, coffee, tea, cacao, and wine; probiotics and vitamins in the prevention of stroke, age-related cognitive decline, and Alzheimer disease. Revue Neurol. 175, 724-741. https://doi.org/10.1016/j.neurol.2019.08.005

Shen R, Luo S, Dong J. 2011. Application of oat dextrin for fat substitute in mayonnaise. Food Chem. 126 (1), 65-71. https://doi.org/10.1016/j. foodchem.2010.10.072

Schultz S, Wagner G, Urban K, Ulrich J. 2004. High-pressure homogenization as a process for emulsion formation. Chem. Eng. Tech. 27 (4), 361-368. https://doi.org/10.1002/ceat.200406111

Štern P, Valentová H, Pokorný J. 2001. Rheological properties and sensory texture of mayonnaise. $E u$ rop. J. Lipid Sc. Tech. 103 (1), 23-28. https://doi. org/10.1002/1438-9312(200101)103:1<23::AIDEJLT23>3.0.CO;2-P

Sun C, Liu R, Liang B, Wu T, Sui W, Zhang M. 2018. Microparticulated whey protein-pectin complex: A texture-controllable gel for low-fat mayonnaise. Food Res. Int. 108, 151-160. https:// doi.org/10.1016/j.foodres.2018.01.036

Worrasinchai S, Suphantharika M, Pinjai S, Jamnong P. 2006. $\beta$-Glucan prepared from spent brewer's yeast as a fat replacer in mayonnaise. Food $\mathrm{Hy}$ drocol. 20 (1), 68-78. https://doi.org/10.1016/j. foodhyd.2005.03.005

Yang Y, Ming J, Yu N. 2012. Color image quality assessment based on CIEDE2000. Adv. Multimedia 2012, 1-6. https://doi.org/10.1155/2012/273723

Zia-Ud-Din, Xiong H, Fei P. 2017. Physical and chemical modification of starches: A review. Crit. Rev. Food Sc. Nutr. 57 (12), 2691-2705. https:// doi.org/10.1080/10408398.2015.1087379 